\title{
The Emergence of Low Carbon Energy Autonomy in Isolated Communities
}

\author{
Callum Rae and Fiona Bradley
}

Department of Architecture, University of Strathclyde, 131 Rottenrow, Glasgow, G4 ONG, Scotland, UK

\begin{abstract}
This study examines the concept of switching from a centralised energy supply model towards a more autonomous model based on the use of low carbon technologies, from the viewpoint of isolated communities in the industrialised world. The study begins by establishing the importance of isolated communities within the field of energy research, and examining the concept of low carbon energy autonomy. It then analyses a number of exemplary case studies from across Europe, all of which have adopted (or are in the process of adopting) a highly autonomous energy supply model based on the use of low carbon technologies.

The communities studied exhibit many of the theoretical challenges and opportunities associated with low carbon energy autonomy, including the potential for stimulating socio-economic development. They also highlight the need for a supportive and structured policy framework and more transparent routes to project funding, in order to lessen the reliance for the success of such projects upon motivated community groups. The role of academia and its relationship with industry was found to be important and the findings call for much greater transparency and knowledge sharing between key stakeholders to facilitate increased development and deployment of low carbon energy autonomy in the future.
\end{abstract}

Keywords: Energy autonomy, renewable energy, remote communities, low carbon technology.

\section{INTRODUCTION}

As part of the response to the triple challenges of growing global energy demand, fossil fuel depletion and increasing GHG emissions, recent decades have seen the gradual emergence of various Low and Zero Carbon Technologies (LZCTs) designed to harness natural energy resources. Significant progress has been made regarding LZCT capability and viability as reliable sources of energy generation and this has led to rapid growth in their deployment around the world, with wind power (arguably the most successful and widespread LZCT) approaching 250,000MW of installed capacity globally. Indeed, such has been the scale of wind energy deployment, the industry has averaged a growth rate of $28 \%$ between 2001-2010 [1].

Whilst the most successful and widespread LZCT deployment has primarily been at a large scale, improvements in manufacturing, economies of scale, miniaturisation and efficiency has meant that smaller scale technologies are now seen as technically and financially viable. The growth of medium to micro scale LZCTs has been supported in many countries through government-led financial incentives, such as the UK's "Feed In Tariff" scheme. Such schemes are common, particularly across Europe, and reflect the importance of the role of smaller scale LZCTs both at present and in the future.

\footnotetext{
*Address correspondence to this author at the Department of Architecture, University of Strathclyde, 131 Rottenrow, Glasgow, G4 0NG, Scotland, UK; Tel: +44 141548 3003; Fax: +44 141552 3997;

E-mail: fiona.bradley@strath.ac.uk
}

This importance partly stems from the introduction of European Union (EU) legislation in recent years, relating to the reduction of energy consumption and greenhouse gas (GHG) emissions, including a specific target of reducing GHG emissions to a level of between $80-95 \%$ of 1990 levels by 2050 [2].

In addition, the EU has agreed a series of ambitious targets for 2020 relating to energy-efficiency and carbon reduction, demanding a $20 \%$ increase in the EU's energy efficiency; a $20 \%$ reduction in GHG emissions (relative to 1990 levels) and an increase in the use of renewable energy to $20 \%$ of total energy generated [3].

This legislation, combined with a growing awareness of global sustainability issues and emission reductions, has incentivised the aforementioned increase in the viability of small to medium scale LZCTs in recent years and this has led to the emergence of autonomous, LZCT-based communityscale energy systems. Many of these low carbon energy autonomy (LCEA) projects have emerged in isolated communities, where access to centralised energy infrastructure is limited. Indeed, more than $50 \%$ of European islands are unconnected to their associated mainland and inevitably in many cases this leaves island communities susceptible to high energy costs [4]. These particular economic, environmental and social challenges coupled with plentiful natural resources have therefore led to good examples of technical innovation and therefore despite the fact that isolated communities represent a small (and 
decreasing) proportion of the industrialised world's total population [5], they have inadvertently emerged at the forefront of LCEA research and development.

Based on an extensive literature review, observation and analysis of three high profile LCEA communities, in isolated locations, this study examines the potential for switching in certain circumstances from the centralised energy supply model which is prevalent in the industrialised world, towards a more autonomous model based on the use of LZCTs.

The main objectives of this study have therefore been to:

1. identify the key contributing factors behind the emergence of low carbon energy autonomy (LCEA) in isolated communities;

2. determine whether or not the theoretical challenges and opportunities associated with such systems translate into "real life" projects;

3. gain insight into the overall effectiveness and socio-economic performance of existing LZCTbased LCEA projects within selected isolated communities;

4. Identify common themes and transferrable outcomes of these projects which could prove useful in future LCEA projects.

\section{ENERGY SUPPLY IN ISOLATED COMMUNITIES}

Despite increasing global urbanisation, the role of isolated communities is considered to be highly significant when it comes to sustainable energy development. This is reflected in the abundance of research projects adopting isolated communities as a vehicle through which to study the application and implementation of alternative and renewable energy sources, including but not limited to [4, 6-11].

Isolated communities can be defined as settlements which are geographically removed from population centres to the extent that they fall outwith the immediate sphere of influence of their nearest population centre(s). The following are listed by $[12,13]$ as being characteristics which can be considered typical of isolated or remote communities:

- $\quad$ Low population density;

- $\quad$ Limited conventional energy resources;
- $\quad$ Lack of infrastructure;

- $\quad$ Low levels of economic activity;

- $\quad$ Physical access constraints;

- $\quad$ Long distances to external markets.

The prominent role of isolated communities within the context of changing energy supply models is largely attributable to these characteristics, as they ensure that isolated communities stand to gain more from increased levels of energy autonomy than other areas of society. This makes isolated communities ideal testbeds for autonomous energy supply models.

\subsection{The Pre-Industrial Energy Supply Model}

In the years preceding the widespread use of fossil fuels, the energy available for human consumption was limited to the following sources:

- $\quad$ plant photosynthesis - energy which is captured by plant life and used to fuel either fire or mechanical work done by humans or by animals;

- $\quad$ The elements - via early wind, solar, run-of-river and tidal energy installations.

These sources were the basis for what Wrigley defines as 'organic economies', and served to place considerable constraints on energy consumption [14]. Trading in fuels during this period was likely to have been confined to a regional scale, given the low energy density of fuels such as fire wood, and whilst the level of energy provision enjoyed by historic communities was not comparable to that of today, it can be seen as being more highly distributed and also more sustainable at a local level. Furthermore, historic isolated communities often had access to greater levels of energy resources (such as wood fuels, crops and peat) than those in urban areas, a disparity which has long since been reversed, with modern-day population centres currently having greater and wider access to energy resources.

\subsection{Industrialisation and the Emergence of the Current Model}

During the industrial revolution of the $19^{\text {th }}$ Century, fossil fuels provided access to highly concentrated quantities of photosynthesised energy, thereby breaking the cycle of reliance on short-term crop yields. With a seemingly abundant supply of high energy fuel, combined with rapid scientific and engineering 
advancement inventing varied technologies for utilising it, industrial productivity soared. This period marked the beginning of mankind's dependence on fossil fuels, and also the beginning of a rapid centralisation of population in industrialising countries. Inevitably, access to energy sources was greater in population centres than in isolated rural areas and therefore rural communities were essentially 'left behind' as the industrial age gathered momentum across Europe. The establishment and later expansion of national centralised energy supply and generation infrastructure in the $20^{\text {th }}$ century partly addressed this disparity, but the high cost of extending grid infrastructure to small and remote communities ensured that many communities remained without access to grid electricity.

Since the establishment of large, centralised energy models, energy supply in isolated communities has therefore been characterised by a reliance on energy imports from population centres. These imports typically consist of fossil fuels, such as diesel for the running of generators for electricity, or fuel oil for use in heating system boilers.

\subsection{Issues Resulting from the Current Model}

In an attempt to improve security of supply and move away from a reliance on fuel imports across national boundaries, efforts have been made in recent years to integrate increasing amounts of renewable energy generation into national energy networks. Although this reduces a country's vulnerability to the geo-political instability which surrounds fossil-fuel rich regions [15] and attempts to address the inherent scarcity of fossil fuels (being a finite resource), this change towards LZCT-based generation can give rise to other security of supply concerns at a regional level, rather than an international level [16]. For example, the disruption of transportation supply routes due to adverse weather conditions, or the reliance on delivery methods which are unreliable can cut communities off from their source of supply. Ironically, despite the high quality and quantity of renewable energy resources being available in remote/isolated areas, the centralised nature of existing infrastructure makes it illequipped to exploit these often vast resources.

Another major impact of the centralised energy supply model is its tendency to contribute towards the centralisation of population, as young members of isolated communities are attracted by improved employment prospects and a perceived higher quality of life in urban population centres. This results in a 'talent drain' that sees young, skilled workers migrate to urban population centres with a resultant 'greying' effect on the remaining population. This trend is exacerbated by the decline in traditional rural industries such as agriculture, mining and fishing [17]. Unfortunately, these trends are expected to continue, negatively impacting on the socio-economic conditions within isolated communities.

\section{TOWARDS LOW CARBON ENERGY AUTONOMY}

Energy autonomy can be defined as "the ability of an energy system to function (or have the ability to function) fully, without the need of external support in the form of energy imports through its own local energy generation, storage and distribution systems" [18]. This has clear links to the general concept of autonomy and as this section will show, the concept is highly interlinked with other local economic and social factors. LCEA then, can be thought of as energy autonomy which is achieved through the use of on-site LZCTs.

\subsection{Advantages and Opportunities}

As discussed in section 2.2, isolated communities are particularly badly served by the prevailing energy supply model. However, in recent years the emergence of LZCTs has provided increasingly viable alternatives to the existing centralised model. This section discusses the range of factors which make many isolated communities ideal for the deployment of LZCTs, with opportunities for creating highly autonomous energy systems.

\subsubsection{Renewable Energy Resources}

Remote areas tend to have greater access to renewable energy resources than others due to favourable climatic conditions and a greater exposure to the elements, due to a lack of interference by human development and the built environment. In addition, low population density in isolated regions means that they have a reduced likelihood of anthropogenic resource depletion e.g. the shading/sheltering effects of buildings for solar/wind energy. This presents one of the principle limitations of the current centralised energy supply model - that its infrastructure is often poorly equipped to utilise these energy resources. The benefit of improving the infrastructure in order to enable it to harness these resources is often outweighed by the cost of doing so, meaning that renewable resources remain untapped. 


\subsubsection{Energy Security}

As discussed in section 2.2, security and reliability of energy supply is an important issue in many isolated communities. Even those which do benefit from a connection to national grid infrastructure are often subject to a poorer quality of supply than those in more urban areas due to weakness (and therefore unreliability) in infrastructure.

Despite the inherent intermittency of renewable energy resources, they have been shown to be capable of providing an adequate degree of security of supply [19] that is equal to (or even surpasses) that of the current model, provided that adequate storage and system management are used [20].

\subsubsection{Cost of Energy}

Whilst the cost of energy from LZCTs can be high in comparison to that from grid supplied or off-grid fossil fuel based supply, recent years have shown a marked decrease in the cost of renewable energy [21, 22]. This translates into lower purchase costs and therefore a lower energy cost for the consumer. This gradually increasing financial viability is likely to be compounded by ever rising fossil fuel costs [23] which, when coupled with the geo-political security of supply concerns highlighted above, serve to further incentivise LCEA.

\subsubsection{Socio-Economic Impact}

Existing energy supply models in isolated communities can contribute towards some negative socio-economic consequences. The introduction of a more autonomous, LZCT-based model could therefore play an important role in reversing these trends and have a positive impact on communities. This view is widely supported by the literature [11, 24-26].

Among the potential benefits that can result from the deployment of LZCTs as part of a LCEA supply model are:

- $\quad$ Support for domestic and local industry, through job creation and the increased productivity that comes with improved reliability and reduced cost of electricity supply;

- A reverse of the 'greying' population trend by making communities a more attractive prospect both for local young people (perhaps returning from education or looking for employment) and for prospective new residents and visitors;
- Diversification of local industry and land use, thus adding a new dimension to the local economy.

- Potential for development and growth of sustainable tourism [27].

However, as pointed out by both Del Rio and Burguillo [26, 28] and Kaundinya [29], the potential benefits such as those listed above, while perhaps being broadly applicable, are highly case-specific and must be examined in sufficient detail before being associated with any individual community.

\subsubsection{Community Ownership and Stakeholder Engagement}

A distinguishing feature of LCEA is the potential for community ownership, which grants the community the opportunity to exert greater control over the design and operation of the local energy system than can be achieved under 'conventional' ownership models. Crucially, it also gives the community greater access to the financial benefits that can result.

Community ownership has been used to successfully incentivise the use of medium to large scale wind energy installations in many European countries. Denmark is a notable example, with community partnerships owning an estimated $80 \%$ of Denmark's wind capacity. In addition to bringing significant financial benefits to the participants, this has helped develop the Danish wind energy industry into a world leader. Community ownership can result in a host of local economic and social benefits such as job creation, an increased sense of community and a more positive perception of LZCTs [30] thereby adding social autonomy to the concept of energy autonomy. Community ownership also appears to incentivise technological change, whilst creating a more positive view of the concept of autonomy, and the use of LZCTs. This argument is supported by Warren and McFadyen [31], who found that communities were less resistive to LZCT development (in the form of wind turbines in this case) if they knew that their community was directly benefitting from their deployment.

\subsection{Disadvantages and Challenges}

Despite being advantageous in some regards, there are also a number of disadvantages and challenges associated with LCEA. These act as barriers to its development and deployment. 


\subsubsection{LZCT Costs}

Chief among these drawbacks is the cost of LZCTbased energy systems, which despite increasingly efficient manufacturing techniques and improved performance, often have a higher cost per unit of energy delivered, than conventional grid-supplied energy. In off-grid or stand-alone systems, the need for energy storage represents a significant additional cost that is not required in grid connected systems and this is discussed in more detail in the following section. The funding of LZCT-based systems also differs from that of conventional fossil fuel-based systems in that costs are largely 'front loaded' i.e. the initial capital cost of the system components themselves represents the majority of the investment required. This disparity stems from the fact that the purchase of fuel is not required for such systems, but represents a significant proportion of the lifetime cost of fuel-based energy systems. This difference is shown in the following figures, which show the cash flow associated with two different energy supply scenarios for the isolated village of Sicud, on the island of Palawan in the western Philippines. These scenarios were developed using a model provided by the developers of HOMER, a software tool developed by the (American) National Renewable Energy Laboratory for the design and analysis of hybrid energy systems [32]. The village comprises a small number of households and has a peak load of less than $25 \mathrm{~kW}$, with the majority of the energy demand occurring during the evening. Figure 1 shows the cash flow associated with a system using diesel generation only, whilst Figure 2 shows the cash

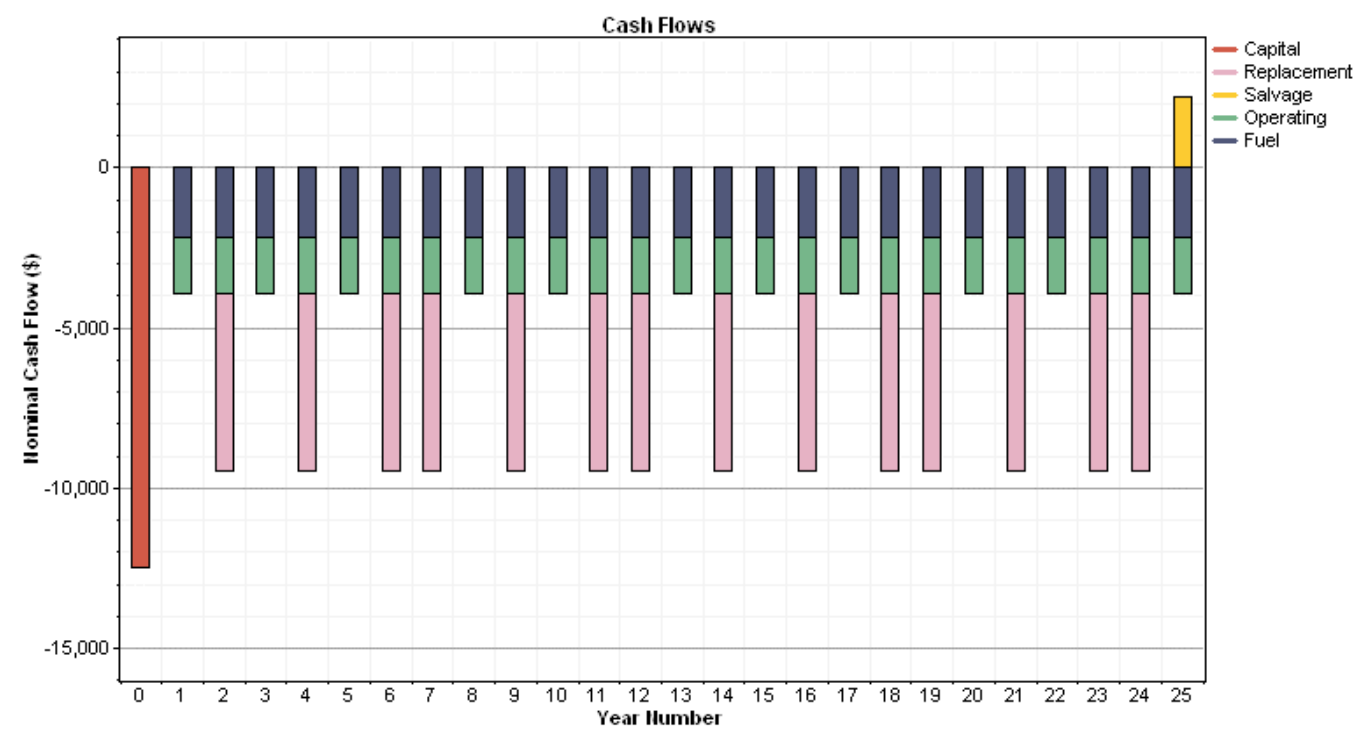

Figure 1: Typical cash flow of "diesel only" energy system.

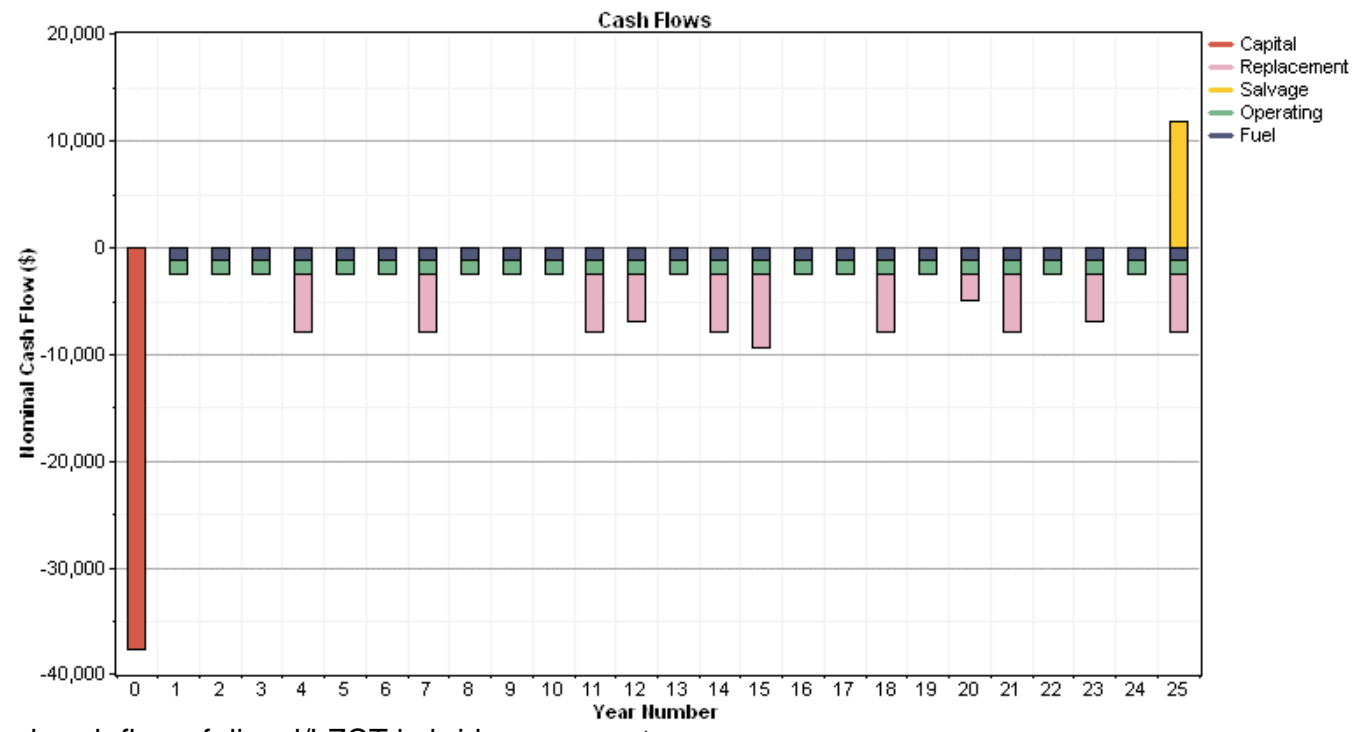

Figure 2: Typical cash flow of diesel/LZCT hybrid energy system. 
flow associated with a hybrid system comprising photovoltaics (PV), wind, battery storage and diesel generation.

Although both solutions have similar Net Present Costs, the capital cost associated with the hybrid system represents a far higher percentage of the total project cost $(45.9 \%)$ than in the "diesel only" system (14.3\%), whilst fuel costs represent just $15.5 \%$ compared to $27 \%$ in the "diesel only" system.

Another economic disadvantage is the current disparity between the level of subsidies enjoyed by the fossil fuel industry and the renewable energy industry. In 2009, global fossil fuel consumption subsidies were approximately $\$ 312$ billion whilst renewable energy only received $\$ 57$ billion [23]. This has a direct effect on energy costs from these sources, and illustrates the extent of the governmental support currently (and also historically) received by the fossil fuel industry.

Furthermore, the cost of developing the innovative and (therefore expensive) methods of extraction required to utilise new fossil fuel reserves can also potentially be passed on to consumers.

\subsubsection{The Intermittency of Renewables}

The inherent intermittency of many renewable energy sources presents a number of challenges for energy systems which rely on them. As discussed by Rae and Bradley [18], the basis for any energy system is the process of matching demand with supply. In systems which feature significant amounts of renewable energy from intermittent sources e.g. solar, wind or tidal energy, some form of energy storage is usually required in order to ensure that any excess energy which is produced can be stored for use during periods when demand exceeds supply. This is particularly relevant in smaller off-grid energy systems, where variation in patterns of demand is greater than in other areas, and its impact on the balance of the system is therefore also greater [33]. Energy storage therefore remains a key research area in the field of stand-alone energy systems research, with many of the currently available storage solutions being widely acknowledged as underdeveloped, inefficient and expensive.

\subsubsection{Resistance to Renewables}

The deployment of LZCTs can be subject to opposition from various sources stemming from objections to one or more of the following:
- Threat posed to local ecosystems, wildlife, plant life etc through loss of habitat, noise disruption or physical threats from moving parts;

- $\quad$ Negative visual or aural impacts;

- Threat to local air quality (in the case of combustion-based technologies such as biomass);

- Objections relating to the role of LZCTs in the energy supply mix.

This can pose an obvious and significant barrier to the adoption of a LCEA model.

\subsection{Perception and Behavioural Change}

As we have seen, the emergence and continued progression of LCEA depends on techno-economic factors relating to LZCT capability and performance. However, there are also a number of less tangible but equally important social factors which affect the way in which the concept of LCEA is compared to alternative energy supply models, and the extent to which it is embraced by society.

Whilst technological advancements are increasing the viability of LZCTs, technological improvements in themselves do not guarantee increases in their deployment. Rather, it is the complex and often uncertain issue of human behaviour that often has the definitive say when it comes to the ultimate success of any low carbon community energy project [34]. This can largely be attributed to the increased impact that user behaviour and energy consumption patterns have on 'off-grid' energy systems. The key difference is that grid-connected consumers have access to a perceived unlimited supply of energy, which can be accessed at any time from a network within which individuals represent a miniscule fraction of the total number of users served. In an autonomous community energy system however, a single user represents a much greater faction of the total demand base, which means that their behaviour has much greater potential to upset the balance of the system. Furthermore, a smaller number of consumers located within a single locale are far less likely to exhibit the type of demand diversity which is associated with nationwide networks. Similar patterns of community consumption can lead to unfavourable 'spikes' in demand, which can place community scale LZCT-based energy systems under considerable strain. 
There are two scenarios for avoiding such problems, the first of which involves sizing LCEA systems to be capable of withstanding these demand spikes. Whilst this solution may not place any restrictions on the user, such a strategy tends to result in over-sizing and inefficient operation, which can lead to higher purchase and running costs, excessive plant wear and even reduced system capability [35].

The alternative is therefore to place some form of control/constraint on consumption, with the aim of improving the temporal and magnitudinal match between energy supply and energy demand. This is known as Demand Side Management (DSM), and is seen as being highly relevant within the context of autonomous energy systems, where the grid cannot be used to lessen the impacts of demand/supply mismatches. As a result, DSM is used to varying extents in existing examples of LCEA, and this is discussed in more depth in the following section. The challenge for regulators and system designers is to implement DSM in a way that minimises perceived restrictions for the user.

Consumer behaviour in LCEA systems is therefore particularly important, and literature in this area supports the need for behavioural change to accompany technological change [36]. Education is regarded in the literature as being as the best way to bring about such change [25, 37, 38].

\section{CASE STUDIES IN LOW CARBON ENERGY AUTONOMY}

Having examined some of the contributing factors behind the emergence of energy autonomy projects in isolated communities; this section provides a more detailed look at three selected European examples, namely:

\section{- $\quad$ Samsø, Denmark; \\ - $\quad$ Eigg, Scotland; \\ - $\quad$ El Hierro, Spain.}

These communities have been chosen due to their different geographical locations and therefore climatic conditions and they also differ with respect to their population size and in the scale and capability of their respective energy systems. Importantly, they are all isolated and have recently made or begun the transition from energy import reliance towards a more autonomous energy model. They have also been selected because they are widely known and are high profile examples of LCEA in isolated communities. (Section 5.1 discusses the scarcity of detailed and technical information relating to LCEA projects and this key factor has also influenced the selection of these case studies.)

\subsection{Samsø, Denmark}

The island of Samsø lies around 10 miles east of Denmark's Jutland peninsula and is home to around 4,000 inhabitants.

In 1997, the island won a national competition to become Denmark's 'Renewable Energy Island'. Until then, Samsø had been entirely dependent on energy imports in the form of coal and oil for its heating and on electricity supplied via a subsea cable connecting it to

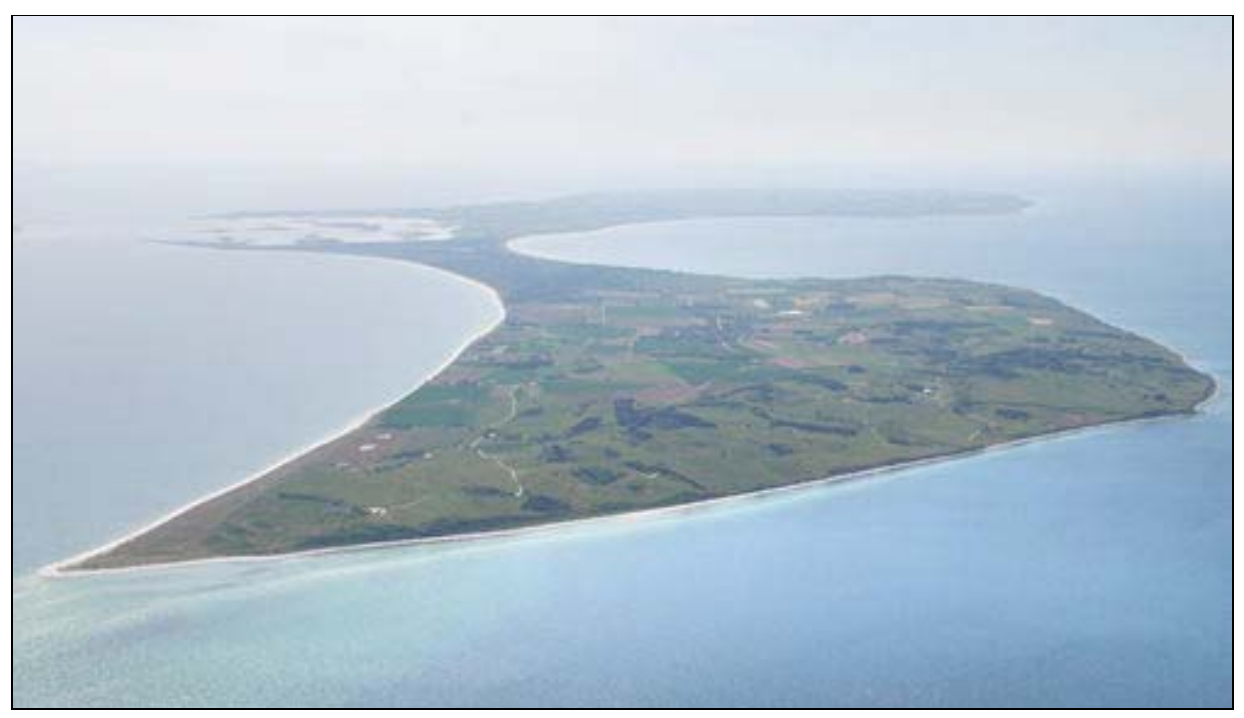

Figure 3: Aerial photograph of Samsø. 
the mainland. Upon winning the award, the community set about implementing a number of low carbon technologies and initiatives with the aim of lessening the island's reliance on fossil fuel imports, and therefore its associated carbon emissions.

Today, Samsø (Figure 3) is a net exporter of energy and claims to have reduced its associated carbon emissions by $140 \%$ (the reduction of over $100 \%$ is possible through the export of wind energy, with surplus being exported to the Danish mainland). Thermal demand has also been addressed, with around $70 \%$ of the island's demand currently being met using renewable sources.

The key elements which comprise the energy system on Samsø are shown in Table 1.

As can be seen above, individually owned installations account for around $9 \%$ of the total installed capacity, meaning that the remaining $91 \%$ is under the control of the community as a whole.

In addition to the obvious environmental benefits, the switch to a highly autonomous energy model has also brought numerous economic advantages. In order to ensure that the transition towards energy autonomy (which took around ten years to complete) had a minimal negative impact on the island's economy, a concerted effort was made to engage the various members of the community at every stage. This included re-training local tradesmen and craftsmen, who were encouraged to adapt their expertise to include the renewable systems being deployed. This helped to avoid unnecessary job losses and also helped build up local knowledge and expertise, which lessened the need for external assistance. Such a strategy is an effective illustration of the importance of the social impacts associated with wholesale changes, and provides insight into how the concerns and vulnerabilities of stakeholders can be addressed when it comes to significant technological transitions.

Perhaps crucially, the island's economy has also benefitted from the potential for considerable income generation across the community as a whole, and not just for the few who can afford to make sizeable investments. It should be noted that resulting income is not evenly distributed between all members of the community, but a community ownership scheme has helped to fund the purchase of the island's wind turbines, with two of the eleven onshore wind turbines owned by a local association whose 5,400 shares are divided between the 450 members [39]. The remainder of the turbines are owned by local farmers.

The sale of excess wind generation, which is sold back to the Danish grid, has brought additional income to the island, some of which is diverted to the continued development of new and ongoing projects relating to energy consumption and island autonomy. The job creation as a result of the Renewable Energy Island project has been estimated at 20 man-years of employment between 1998 and 2005 [38]. The economic and social benefits are starting to address the long term depopulation which has been an issue on the island - to date, the project has maintained both Samsø's resident population, as well as attract new potential residents and the island has additionally

Table 1: Samsø Energy System Summary

\begin{tabular}{|c|c|c|c|}
\hline LZCT type & Per unit capacity & No. of units & Total capacity \\
\hline Wind (onshore) & $1 \mathrm{MW}$ & 11 & 11 \\
\hline Wind (offshore) & $2.3 \mathrm{MW}$ & 10 & 23 \\
\hline Biomass (straw) DH & $3 \mathrm{MW}$ & 1 & 3 \\
\hline Biomass (straw) DH & $1.6 \mathrm{MW}$ & 1 & 1.6 \\
\hline Biomass (straw) DH & $0.8 \mathrm{MW}$ & 1 & 0.8 \\
\hline Solar/woodchip DH & $1.6 \mathrm{MW}$ & 1 & 1.6 \\
\hline Solar thermal & \multirow{4}{*}{ Individual small/micro scale units } & \multirow{4}{*}{ Estimated 300 households } & \multirow{4}{*}{$\sim 4^{*}$} \\
\hline Heat pump & & & \\
\hline Solar thermal & & & \\
\hline Wood pellet boiler & & & \\
\hline \multicolumn{3}{|c|}{ TOTAL Installed LZCT Capacity (MW) } & 45 \\
\hline
\end{tabular}

*Based on kW/DH consumer values, applied to 300 estimated households. 
enjoyed increased visitor numbers in recent years. This is reflected in the fact that in 2005 , permission was granted for the construction of a further 50 permanent homes and 100 holiday homes [40].

The Sams $ø$ community's transition towards LCEA is a continuous and ongoing process. Focus has now turned to eliminating the use of fossil fuels altogether This vision, dubbed "Samsø 2.0" is set to include a number of trial/demonstration projects which include biodiesel and hydrogen fuelled transport initiatives, as well as replacing all existing fossil-fuel based heating systems with LZCT alternatives [41]. In addition to providing further local socio-economic benefits (job creation, reduced cost of energy), this scheme hopes to maintain the island's standing as a centre of excellence in the area of LCEA.

\subsection{Isle of Eigg, Small Isles, Scotland}

Home to a permanent population of around 90, the island of Eigg (Figure 4) lies around 7 miles off Scotland's West coast. The island and its inhabitants rose to prominence in 1997 when Eigg Heritage Trust succeeded in one of the first community land buy-outs of its kind in the UK.

One of the first issues to be addressed by the islanders following the buy-out was the island's energy supply. Islanders on Eigg had historically relied on peat, wood and hydro power as the basis for their energy supply, with coal gradually replacing peat as supplies of peat on the island ran low and coal became more affordable. In the decades preceding the buy-out, islanders relied mainly on diesel and kerosene fuelled generators, though there were a small number of privately owned micro-LZCTs and the use of coal had continued [42].

The project, which became operational in 2008, was established by Eigg Electric Ltd (a subsidiary of Eigg Heritage Trust). The system features a combination of wind (Figure 5), solar and hydro power. The initial photovoltaic array of $9.9 \mathrm{kWp}$ has since been expanded to $30.9 \mathrm{kWp}$, with plans to add a further $22.5 \mathrm{kWp}$ of capacity in 2013. Battery storage (Figure 6 ) and backup diesel generators were included in order to ensure reliable, 24 hour power. The system's principle components are listed in Table 2.

The power produced by the system is distributed around the island via a high voltage underground grid that serves the electrical needs of the island's homes and businesses. Electric heaters located in the island's public buildings serve as a means of dumping excess energy during times of surplus.

Eigg Electric placed a high importance on autonomy from mainland assistance and expertise, and throughout the design stage every effort was made to

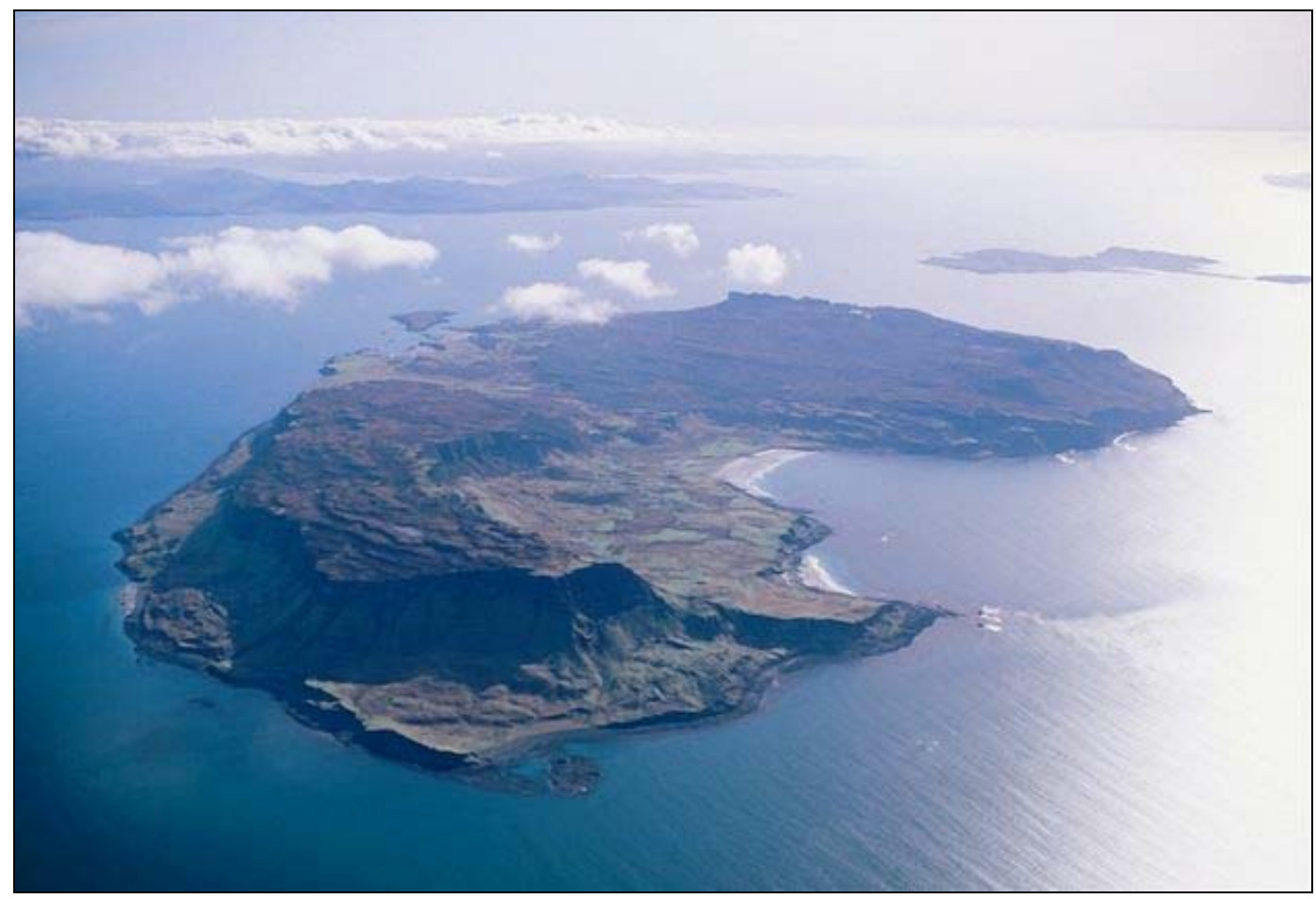

Figure 4: Aerial photograph of Eigg. 


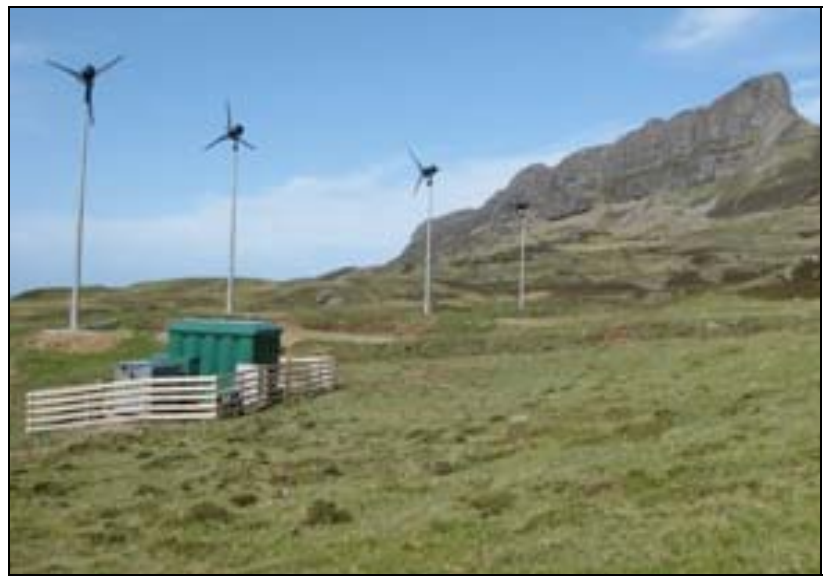

Figure 5: Eigg's 4 x 6kW wind turbines.

ensure that the company (through its various paid and unpaid staff) would be able to operate and maintain the system independently. This involved a stipulation that the various system installers who visited the island provided training and conducted question and answer sessions with the Eigg Electric maintenance team. Team members also undertook a safety course (funded by Eigg Electric Ltd) to enable them to work safely with high voltages. The body of knowledge and expertise built up through this hands-on approach to the island's energy system during its early years of operation means that to date, there been no fault that hasn't been fixed within 24 hours of discovery.

An important factor in the design and ongoing operation of the system is cost minimisation. From the outset, there was a strict and limited project budget. The budget was sufficient to provide a system that would meet the desired level of reliability and energy provision, but only if costs were minimised wherever possible. During the design and construction phases of the scheme the islanders contributed wherever possible, thus lessening reliance on external and expensive contractors. Work done by the islanders included planning applications, road surveys, way marking and project management. Cost minimisation

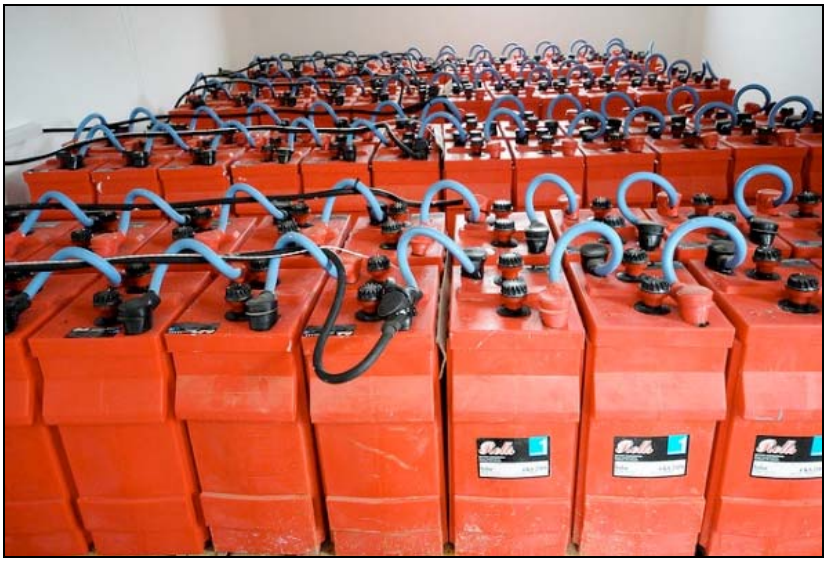

Figure 6: The battery bank used on Eigg.

measures have also extended into the operation of the system. For example, the choice of pre-paid energy cards for the purchase of electricity means that the administrative and personnel costs associated with billing and dealing with late/missed payment are avoided.

The Eigg Electric system has significantly improved the quality of life of its residents and as a result, the island is seen as a more attractive prospect for both visitors and prospective residents. There has been a reversal of the island's depopulation, partly attributed to the availability of reliable, 24 hour power, although the role played by a change in the island's housing policy, alongside other factors, should also be acknowledged. A population of 67 in 2001 [43] has now increased to around 90 people and the island has received a greater amount of visitors following the electrification project. This is attributed to the ability of local businesses to offer an improved quality of service, thanks to 24 hour power, and the fact that the energy system itself attracts significant academic and 'green tourism' interest from around the world.

The economic benefits of the system extend beyond tourism however. Eigg Electric employs six members of staff on a part-time, hourly basis to perform ongoing

Table 2: Eigg Energy System Summary

\begin{tabular}{|c|c|c|c|}
\hline LZCT type & Per unit capacity & No. of units & Total capacity \\
\hline Wind (onshore) & $6 \mathrm{~kW}$ & 4 & 24 \\
\hline Photovoltaic & $180 \mathrm{~W}$ & $172^{*}$ & 30.9 \\
\hline Hydro turbine (micro) & $5 \mathrm{~kW}$ & 2 & 10 \\
\hline Hydro turbine (main) & $100 \mathrm{~kW}$ & 1 & 100 \\
\hline \multicolumn{3}{|c|}{ TOTAL Installed LZCT Capacity (kW) } & 164.9 \\
\hline
\end{tabular}

*Number of modules calculated using known capacities of individual units and total array. 


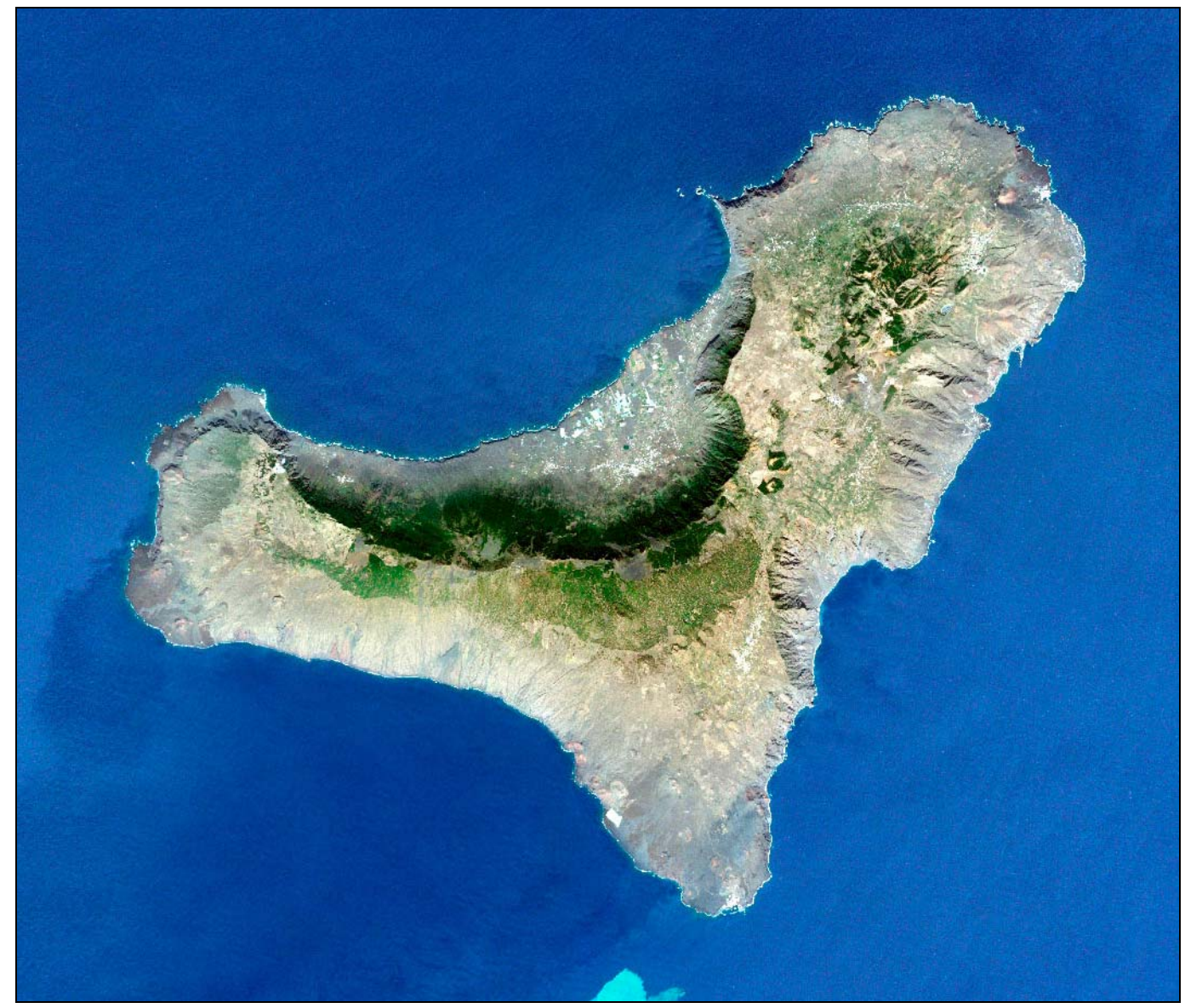

Figure 7: Aerial photograph of El Hierro.

operational and maintenance duties and their wages come from company profits from the sale of energy, which is charged at a flat rate $0+f 21 \mathrm{p} / \mathrm{kWh}$. This tariff rate was designed to cover the operation and maintenance costs of the system, whilst also allowing a separate fund to be built up to carry out major repairs and replace components, thus helping to ensure the longevity of scheme. The cost of electricity for the islanders is estimated to be approximately $1 / 3^{\text {rd }}$ of what it was previously. Energy is also more reliable, now that the island is no longer dependant on fuel deliveries from the mainland, which were subject to cancellation due to adverse weather conditions.

\subsection{El Hierro, Canary Isles, Spain}

The island of El Hierro (Figure 7) is the smallest and Westernmost of the Canary Islands. Being mountainous and volcanic, the majority of its $\sim 11,000$ inhabitants are confined to its coastal regions.

The "El Hierro 100\% Renewable Project" was initially discussed as early as 1986, but not approved definitively until June 2002 as part of a Management Island Plan [44]. The project aims to increase the island's level of energy autonomy by utilising its considerable renewable energy resources, particularly wind and the potential for hydro power. Excess energy from the wind farm (Figure 8) is used to pump stored water to an upper reservoir (Figure 9) for use in a hydroelectric plant, with a pre-existing diesel plant being kept for use as back up [45]. Table 3 outlines the main elements that comprise the system. Consumer owned installations are not included, due to a lack of reliable data.

The system is due to become operational in March 2013 and is expected to produce around 48GWh annually, enabling the island to reduce its diesel imports by around 6,000 barrels each year, thereby offsetting around 18,200 tons of carbon dioxide emissions each year [44]. Other elements of this innovative project include the deployment of gridconnected photovoltaics and the use of solar thermal technologies by individual consumers, to try and meet the hot water and heating demands which are not served by the main wind-hydro system. Plans are also in place to replace the 6,000 cars on the island with electric alternatives. 


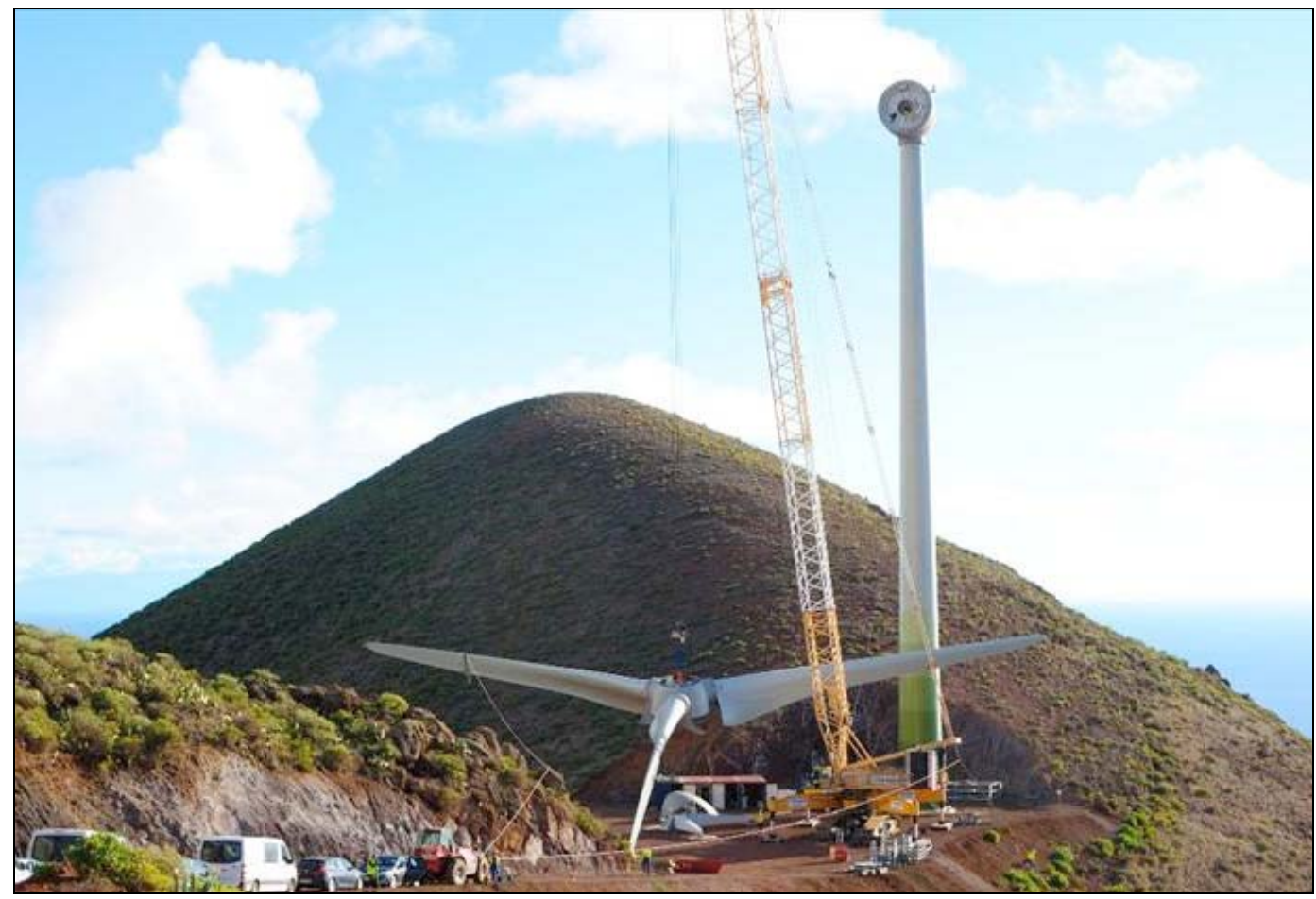

Figure 8: The assembly of one of the El Hierro system's five turbines.

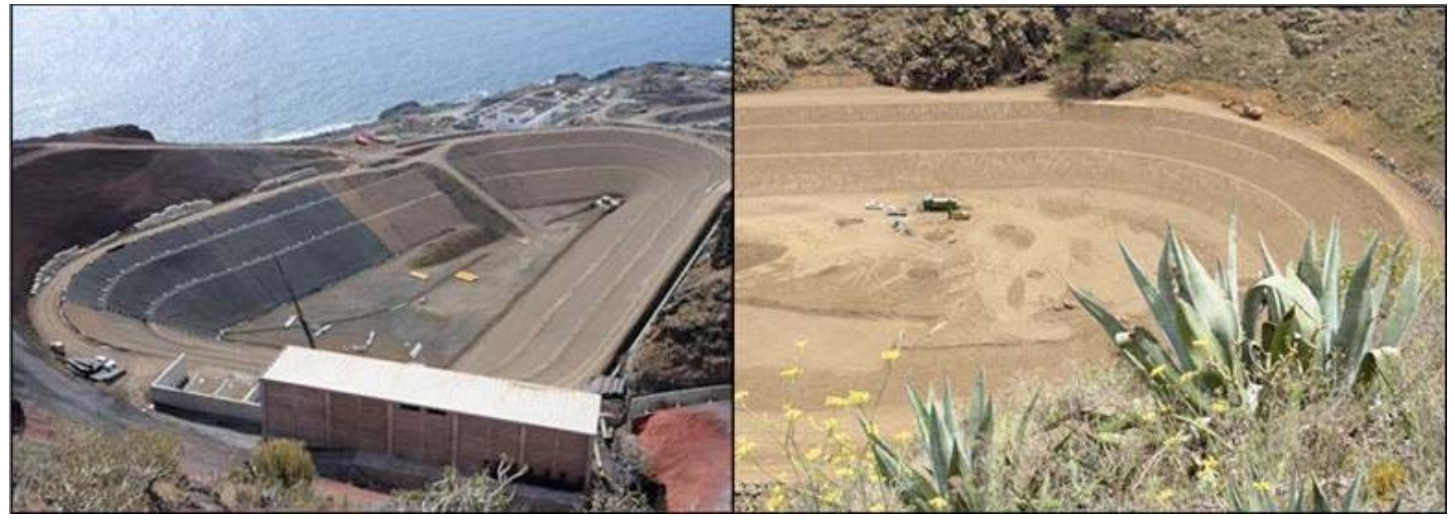

Figure 9: El Hierro's lower (left) and upper (right) water storage reservoirs.

Table 3: El Hierro Energy System Summary

\begin{tabular}{|c|c|c|c|}
\hline LZCT type & Per unit capacity & No. of units & Total capacity \\
\hline \hline Wind (onshore) & $2.3 \mathrm{MW}$ & 5 & 11.5 \\
\hline Hydro & $11.3 \mathrm{MW}$ & 1 & 11.3 \\
\hline Diesel Gen. & $12.7 \mathrm{MW}$ & 1 & 12.7 \\
\hline \multicolumn{2}{|c|}{ TOTAL Installed LZCT Capacity (MW) } & 35.5 \\
\hline
\end{tabular}

As with the previous examples, the outcomes that result from increased energy autonomy on El Hierro are many and varied - chief among these is the economic impact. Estimations place the savings from the aforementioned reductions in diesel consumption at around $€ 1.8 \mathrm{~m}$ each year [44] and the project has additionally created a number of local jobs, ranging from the construction of the system to its ongoing maintenance and operation thus diversifying the local economy. As with the Samsø example, the 
international notoriety that comes with being a prominent example of island self-sufficiency and sustainability is also expected to bring economic benefits in the form of green tourism opportunities, as well as the potential for academic and industrial investment and collaboration.

With an investment cost of $€ 65 \mathrm{~m}$ - which equates to around $€ 5,900$ per inhabitant - the cost of the project is relatively high compared with mainland supply costs, with obvious disadvantages arising through unfavourable economies of scale. As we have seen in the other examples however, pre-existing electricity prices on El Hierro were comparatively high $(€ 0.242 / \mathrm{kWh})$ and subject to future uncertainty given the source of the diesel fuel imports. When the average generation cost of onshore wind energy projects is taken into consideration (between 0.045 and $€ 0.087 / \mathrm{kWh}$ - figures correct as of 2009 [46]) the scope for potential reduction in energy costs becomes apparent. These factors lessen the impact of the high investment cost, and effectively improve the perceived economic viability of the system. However, it should be noted that energy pricing under the new supply model is yet to be announced, and there is no guarantee that the savings resulting from the change will be passed on to consumers.

By switching its reliance from externally sourced fossil fuels to its own renewable energy resources, El Hierro has insulated itself from the uncertainty that arises from current and future geopolitical instability, as well as freeing itself from the rising cost trend associated with finite resources. This makes the longterm cost of energy more accurately predictable, although it should be noted that the operational life expectancy and performance of hybrid renewable systems is, to an extent, still uncertain.

\section{DISCUSSION OF FINDINGS}

The case studies featured in this study have provided examples of some high profile cases of LCEA in isolated communities. This section discusses the findings of these case studies, in order to establish their relevance within the wider context of global energy development and identify outcomes which could inform the future of LCEA.

\subsection{Common Themes}

Although several papers have been published relating to renewable energy penetration in Mediterranean islands such as Crete, Sicily and
Gavdos $[4,11,28]$, the authors found a surprisingly low volume of detailed academic and publicly available information relating to LCEA in isolated communities. This suggests that whilst projects themselves have been undeniably successful in many areas, more partnerships with academia could be developed to offer advice and analyse the data from pioneering examples. Critical academic focus on LCEA in isolated communities is not reflected in the literature until around 2006 and these case studies are inevitably early LCEA examples. The majority of the documentation therefore comes from either the communities themselves or from the industry partners involved in the design and construction of the systems (as was the case in Eigg and Samsø). Whilst such industry involvement is obviously crucial in such projects, the competitive nature of industry has perhaps led to a lack of detailed and widely available information. This also illustrates the relatively recent emergence of LZCTs as a viable way of achieving energy autonomy.

A common theme between the three case studies is the importance of the cost of energy. In all three cases, a higher degree of energy autonomy through the use of LZCTs will have resulted in a reduction in the cost of energy to the consumer. This is contrary to some beliefs that LCEA results in energy price rises to account for high initial equipment costs. This therefore suggests a greater degree of financial viability and also highlights the fact that in many cases (including the case studies featured) energy prices under the previous energy model had reached a non-viable level.

LCEA improves the security of supply, and the introduction of more self-sufficient energy models appears to increase levels of social and economic autonomy within the community. In the case of Sams $\varnothing$, after the completion of the initial LCEA project, secondary projects and initiatives were started with the aim of continuing the shift towards complete energy autonomy.

Significant reliance on external sources of funding was another common theme across the case studies examined. As expected, the initial costs (from design through to installation) represent the vast majority of the system costs and require sums that could never realistically be raised without considerable external funding. The majority of project funding for these projects therefore came from government or European grants, which in the case of Samsø were only made accessible through winning a competition. In all three 
cases, the case studies effectively represent 'one-off' projects, and whilst this is understandable due to their pioneering nature as 'early adopters' of LCEA, securing the levels of funding required did represent a significant challenge. This points towards a need for policy makers to provide a more supportive and structured approach to community energy project funding to ensure that in the future it is available to more than just the most organised and highly motivated communities.

Another common theme was the limited extent to which the motivation behind the featured projects was rooted in environmentalism/climate change mitigation. This is perhaps contrary to their wider public perception, with all three examples having gained considerable notoriety in environmentally focused areas of the written (and in particular online) media. Although the concept of sustainability does play a role in the motivation behind these projects, the prospect of financial savings and local socio-economic benefit appears to be the primary motivation. This is illustrated by a slogan used by the people of Samsø: "think local act local" [40]. To a certain extent, the international acknowledgement gained by these projects has therefore potentially arisen through a subtle misrepresentation of their motivations. This appears to contradict the notion of such projects being routed in wider, global sustainability, and is reflected in the recent literature in this area [4, 28, 47-49] which highlight the many and varied motivations that affect individual, community and local government energy preferences. The importance of community consultation on matters relating to the adoption of a LCEA model cannot be over-emphasised. Indeed, a recent study found that at the present time local issues are dominating renewable energy implementation but unfortunately EU policy is providing little support for them [49].

Samso, Eigg and El Hierro have all exhibited a strong link between the energy supply model and the local social and economic conditions. This link is often stronger in rural communities compared to urban areas, and can come to characterise or even define an isolated community. While this is arguably more likely in high profile case studies, the potential for social and economic prospects to be bolstered through community organisation and a common goal should not be discounted. LCEA can therefore be regarded as an important tool for driving social and economic regeneration in remote locations. Indeed, in Eigg and Samso which have had time to establish themselves, there has been an increase in population which has been attributed primarily to the adoption of LCEA.

Whilst the benefits of LCEA projects are many and varied, the out-sourcing of jobs to external contractors can lead to some of the socio-economic benefits being diverted elsewhere. The scale of the work involved in implementing LCEA seems to be decisive when it comes to ability of the local community to engage in its design and construction. In Eigg for example, the local community had a large say in the design of the system components and in the ongoing management of the project, with local labour and expertise utilised wherever possible. However, in the cases of Samsø and El Hierro, which are much larger in scale, the ability of the local communities to be so actively involved was limited and the projects' procurement methods and delivery have been more akin to national infrastructure projects. This by-passing of the local community limits their ability to realise some of the related socio-economic benefits, such as job creation and the support of new maintenance and monitoring requirements. The involvement of a local community in all aspects of the project, from design through to maintenance, should therefore be considered essential if the communities in question are to take advantage of the full range of potential benefits. This is consistent with the literature, which also stresses the importance of stakeholder engagement $[15,26]$.

All of the case studies exhibit the characteristics associated with those which are worst served/most marginalised by the prevailing centralised energy supply model i.e. high energy prices, fossil fuel dependence, poor quality of supply and susceptibility to security of supply concerns. Each location also benefits from considerable renewable energy resources (though the nature of these resources differed between the case studies) and share the motivation required to switch to a more autonomous energy supply model. These circumstances combine to create a strong argument for LCEA, and foster a willingness to embrace the changes necessary to realise it. As a result, all three projects enjoy the full support of the vast majority of their local communities.

\subsection{Limitations to Findings}

As with any case study-based investigation, there are limitations to the wider applicability of the findings discussed above.

As discussed in the previous section, some of the information available on the systems of Eigg and 
Samsø is only available through industry partners involved in the schemes, or from the communities themselves. Whilst there is no reason to question the accuracy of this information, it should be noted that it is not subject to verification, and - in the case of industrysupplied data - may represent a 'best case' scenario in terms of system performance, and in particular predicted savings.

The case studies chosen are amongst the first to adopt LCEA on such a scale and to such a degree of sophistication. Not all future LCEA projects will therefore attract the same levels of interest from either the media or, crucially, industry. Indeed, if such projects become more common in the future, then the sources of funding utilised by Eigg, Sams $\varnothing$ and EI Hierro will become more difficult to secure. This underlines the need for the issues of project funding and greater policy support to be addressed.

Whilst LCEA has been shown to be beneficial in isolated communities, not all of the identified benefits can be expected to be replicated in wider society i.e. in grid-connected or urban communities. Here, the disincentives associated with maintaining the status quo are less, resulting in a resistance to change. More urbanised communities are potentially less likely to be willing to accept some of the constraints associated with LCEA, such as the $5 \mathrm{kw}$ domestic consumption cap introduced on Eigg, which was embraced by islanders accustomed to a limited and unreliable power supply. Such restrictions would represent a considerable constraint on communities used to 24 hour 'unlimited' power, and would therefore be met with understandable resistance.

It should also be noted that LCEA is not the only alternative to the status quo. Recent years have seen a concerted effort by national-scale networks to integrate renewable energy sources in an effort to de-carbonise the current model, increase price predictability and lessen the reliance on fuel imports.

It is also important to acknowledge that while the findings from isolated communities may be significant for future LCEA projects, the impact of isolated communities within the wider EU-wide push towards targets relating to community and renewable energy is small, due to their relative size. This is supported by the fact that (as discussed in section 5.1) the primary motivations behind switching to LCEA were socioeconomic as opposed to environmental.

\section{CONCLUSIONS}

This research study has examined the concept of switching from the centralised energy supply model, which is prevalent in the industrialised world, towards a more autonomous model based on the use of LZCTs, based on observations drawn from the emergence of LCEA in isolated communities.

The motivation to undergo such a huge shift has been shown to be the result of a logical choice made in terms of financial and technical viability, rather than perceived environmental benefit or responsibility (although to dismiss this factor altogether, may not be prudent).

Despite increasing interest in the concept of LCEA, there is much still to be learnt by industry, governments and academia, with communities such as those featured in this study often at the forefront of innovation in this area. Transparency and the sharing of findings and information between the various stakeholders is therefore essential if the experiences and outcomes from these early examples are to be built upon.

Academia has become increasingly involved in the various technical, economic and social areas of the field, but has to a certain extent been over-taken by the pace at which real life, industry enabled, examples have emerged. This highlights the urgency with which energy autonomy has been introduced into these isolated communities and shows the level of discontent that exists with the prevailing centralised model.

A common theme that has been revealed by studying the examples presented in this paper is the need for a highly organised and motivated community group. These groups must be capable of building on a collective desire for change and formulating proposals to carry forward to potential project partners whether they are academic, industrial or governmental. This collective aspiration appears to be an important prerequisite for communities moving towards the adoption of autonomous energy supply models as does, the presence of locally abundant renewable energy resources. However, while the viability of each technology may vary with respect to geographical location, each climatic zone could be regarded as having access to plentiful renewable energy resource potential.

Ideally, framework policies should adopt an innovative and proactive approach in order to support LCEA projects, but instead they tend to react to 
pioneering projects, such as those presented in this study. These projects have therefore had to rely on highly motivated community groups and considerable industrial input to overcome the various financial and regulatory obstacles which result from the current lack of a supportive policy environment. The highly case specific nature of these projects appears to exacerbate this issue, making the task of providing support - which is general enough to be broadly applicable, yet specific enough to be tailored to each specific instance - a very difficult one. Nevertheless, policy makers must continue to address these issues if the targets intended to deliver a sustainable energy future are to be met.

Finally, these case studies have all illustrated the wider relevance of LCEA, in that many of the factors which led to a switch to LCEA, such as security of supply concerns, increasing fuel prices and ambitious energy policy targets are global issues and therefore not purely the domain of isolated communities.

\section{REFERENCES}

[1] GWEC. Global Wind Statistics 2011. 2012; 2013 29/1/13.

[2] European Commission. A Roadmap for moving to a competitive low carbon economy in 2050. COM 2011; 112(4).

[3] European Commission. 2020 by 2020 Europe's Climate Change Opportunity. COM 2008; 30.

[4] Michalena E, Tripanagnostopolous I. Contribution of the solar energy in the sustainable tourism development in Mediterranean Islands. Renewable Energy 2010; 35(3): 66773.

http://dx.doi.org/10.1016/j.renene.2009.08.016

[5] worldbank.org. Urban Population (\% of total). 11th December. World Bank 2011; 2012.

[6] Prodromidis GN, Coutelieris FA. A comparative feasibility study of stand-alone and grid connected RES-based systems in several Greek Islands. Renewable Energy 2010; 36(7): 1957-63.

http://dx.doi.org/10.1016/j.renene.2010.12.021

[7] Young DC, Mill GA, Wall R. Feasibility of renewable energy storage using hydrogen in remote communities in Bhutan. Int J Hydrogen Energy 2007; 32(8): 997-1009. http://dx.doi.org/10.1016/j.jihydene.2006.07.002

[8] Gazey R, Salman SK, Aklil-D'Halluin DD. A field application experience of integrating hydrogen technology with wind power in a remote island location. J Power Sources 2006; 157(2): 841-47.

http://dx.doi.org/10.1016/j.jpowsour.2005.11.084

[9] Ntziachristos L, Kouridis C, Samaras Z, Pattas K. A windpower fuel-cell hybrid system study on the noninterconnected Aegean islands grid. Renewable Energy 2005; 30(10): 1471-87.

http://dx.doi.org/10.1016/j.renene.2004.11.007

[10] Duic N, Krajacic G, da Graca Carvalho M. Renewlslands methodology for sustainable energy and resource planning for islands. Renewable Sustainable Energy Rev 2008; 12(4): 1032-62.

http://dx.doi.org/10.1016/j.rser.2006.10.015
[11]

Michalena E, Angeon V. Local challenges in the promotion of renewable energy sources: The case of Crete. Energy Policy 2009; 37(5): 2018-26. http://dx.doi.org/10.1016/i.enpol.2009.01.047

[12] Underwood CP, Ramachandran J, Giddings RD, Alwan Z. Renewable-energy clusters for remote communities. Appl Energy 2007; 84(6): 579-98.

http://dx.doi.org/10.1016/j.apenergy.2007.01.017

[13] Hanley N, Nevin C. Appraising renewable energy developments in remote communities: the case of the North Assynt Estate, Scotland. Energy Policy 1999; 27(9): 527-47. http://dx.doi.org/10.1016/S0301-4215(99)00023-3

[14] Wrigley EA. Energy and the English Industrial Revolution. Philisophical Trans Royal Soc 2013.

[15] Krajačić G, Duić N, Zmijarević Z, Mathiesen BV, Vučinić AA, da Graça Carvalho M, et al. Planning for a $100 \%$ independent energy system based on smart energy storage for integration of renewables and $\mathrm{CO} 2$ emissions reduction. Appl Thermal Eng 2011; 31(13): 2073-83.

http://dx.doi.org/10.1016/j.applthermaleng.2011.03.014

[16] Ofgem. Electricity Capacity Assessment 2012.

[17] DEFRA. Department for Environment, Food and Rural Affairs: Rural Strategy. 17th December 2004; 2012.

[18] Rae C, Bradley F. Energy autonomy in sustainable communities - A review of key issues. Renewable Sustainable Energy Rev 2012; 16(9): 6497-506. http://dx.doi.org/10.1016/j.rser.2012.08.002

[19] Padrón S, Medina JF, Rodríguez A. Analysis of a pumped storage system to increase the penetration level of renewable energy in isolated power systems. Gran Canaria: A case study. Energy 2011; 36(12): 6753-62. http://dx.doi.org/10.1016/j.energy.2011.10.029

[20] Arteconi A, Hewitt NJ, Polonara F. State of the art of thermal storage for demand-side management. Appl Energy 2012; 93: 371-89.

http://dx.doi.org/10.1016/j.apenergy.2011.12.045

[21] Arent DJ, Wise A, Gelman R. The status and prospects of renewable energy for combating global warming. Energy Economics 2011; 33(4): 584-93. http://dx.doi.org/10.1016/i.eneco.2010.11.003

[22] IPCC, Special Report on Renewable Energy Sources and Climate Change Mitigation. United Kingdom and New York, NY, USA: Cambridge University Press 2011.

[23] IEA, World Energy Outlook 2010. Paris 2010.

[24] Roseland M. Sustainable community development: integrating environmental, economic, and social objectives. Progress Planning 2000; 54(2): 73-132. http://dx.doi.org/10.1016/S0305-9006(00)00003-9

[25] Kaplan S. New Ways to Promote Proenvironmental Behavior: Human Nature and Environmentally Responsible Behavior. J Social Issues 2000; 56(3): 491-508.

http://dx.doi.org/10.1111/0022-4537.00180

[26] del Rio P, Burguillo M. An empirical analysis of the impact of renewable energy deployment on local sustainability. Renewable Sustainable Energy Rev 2008; 13(6-7): 1314-25.

[27] Michalena E, Hills J, Amat JP. Developing sustainable tourism, using a multicriteria analysis on renewable energy in Meditteranean Islands. Energy Sustainable Develop 2009; 13(2): 129-36.

http://dx.doi.org/10.1016/i.esd.2009.06.001

[28] del Rio P, Burguillo M. Assessing the impact of renewable energy deployment on local sustainability: Towards a theoretical framework. Renewable Sustainable Energy Rev 2008; 12(5): 1325-44. http://dx.doi.org/10.1016/j.rser.2007.03.004

[29] Kaundinya DP, Balachandra P, Ravindranath NH. Gridconnected versus stand-alone energy systems for 
decentralized power - A review of literature. Renewable Sustainable Energy Rev 2009; 13: 2041-48. http://dx.doi.org/10.1016/j.rser.2009.02.002

[30] Bolinger M. Community wind power ownership schemes in Europe and their relevance to the United States 2001.

[31] Warren CR, McFadyen M. Does community ownership affect public attitudes to wind energy? A case study from southwest Scotland. Land Use Policy 2010; 27(2): 204-13. http://dx.doi.org/10.1016/j.landusepol.2008.12.010

[32] NREL. homerenergy.com." [Online]. Available: http://homerenergy.com/.

[33] Kaldellis JK, Zafirakis D. Present situation and future prospects of electricity generation in Aegean Archipelago islands. Energy Policy 2007; 35(9): 4623-39. http://dx.doi.org/10.1016/j.enpol.2007.04.004

[34] Schweizer-Ries P, Petra S-R. Energy sustainable communities: Environmental psychological investigations. Energy Policy 2008; 36(11): 4126-35. http://dx.doi.org/10.1016/j.enpol.2008.06.021

[35] Fux SF, Benz MJ, Guzzella L. Economic and environmental aspects of the component sizing for a stand-alone building energy system: A case study. Renewable Energy 2013; 55: 438-47.

http://dx.doi.org/10.1016/j.renene.2012.12.034

[36] Schweiker M, Shukuya M. Comparative effects of building envelope improvements and occupant behavioural changes on the exergy consumption for heating and cooling. Energy Policy 2010; 38(6): 2976-86.

http://dx.doi.org/10.1016/j.enpol.2010.01.035

[37] Moloney S, Horne RE, Fien J. Transitioning to low carbon communities-from behaviour change to systemic change: Lessons from Australia. Energy Policy 2009; 38(12): 761423.

http://dx.doi.org/10.1016/j.enpol.2009.06.058
[38] Shamsuzzoha AHM, Grant A, Clarke J. Implementation of renewable energy in Scottish rural area: A social study. Renewable Sustainable Energy Rev 2011.

[39] ens.dk. Samso - Renewable Energy Island. 6th February. Danish Energy Agency 2013.

[40] Jorgensen PJ, Hermansen S, Johnsen A, Nielsen JP. Sams $\varnothing$ - a renewable energy island. 10 years of development and evaluation. no. 18/12/12. PlanEnergi, 2007.

[41] energiakademiet.dk/en. Fossil Free Island. 6th February. Samsø Energy Academy 2013.

[42] Twidell JW, Pinney AA. Energy supply and use on the small Scottish island of Eigg. Energy 1985; I(8): 963-73. http://dx.doi.org/10.1016/0360-5442(85)90008-8

[43] Fleming AD. Scotland's Census 2001: Statistics for Inhabited Islands. General Register Office for Scotland 2003.

[44] evwind.es. The Wind-Hydro-Pumped Station of El Hierro. no. 9th Jan 2013. 2012.

[45] endesa.com. El Hierro 100\% Renewable. 9th Jan 2013.

[46] Blanco MI. The economics of wind energy. Renewable Sustainable Energy Rev 2009; 13(6): 1372-82. http://dx.doi.org/10.1016/j.rser.2008.09.004

[47] Kontogianni A, Tourkolias C, Skourtos M. Renewables portfolio, individual preferences and social values towards RES technologies. Energy Policy 2013; 55: 467-76. http://dx.doi.org/10.1016/i.enpol.2012.12.033

[48] He HZ, Kua HW. Lessons for integrated household energy conservation policy from Singapore's southwest Eco-living Program. Energy Policy 2013; 55: 105-16. http://dx.doi.org/10.1016/j.enpol.2012.10.067

[49] Michalena E, Hills J. Renewable energy issues and omplementation of European energy policy: the missing generation?" Energy Policy 2012; 45: 201-16. http://dx.doi.org/10.1016/i.enpol.2012.02.021 